\title{
SOUTH AFRICAN NAVAL PERSONNEL SECONDED TO THE ROYAL NAVY 1940-1942
}

\author{
by Cdr W.M. Bisset*
}

Statistics of South African naval personnel seconded to the Royal Navy between December 1943 and September 1945 have been published in Annexure $B$ to an article in Militaria $12 / 1$ 1982. Since then I have traced similar statistics in the SADF Archives for June 1940 and June 1941. To these I have added details extracted from the Navy Lists for August 1941 and August 1942.

The publication of this hitherto inaccessible information makes it possible to gain a clearer picture of the important role played by our seconded naval personnel and to see how it changed during the war.

The South African Naval historical Record in- clude the following description of the 28 South Africans serving in HMS Neptune written by the Commanding Officer Capt R.C. O' Conor RN:

'They will prove a real asset to the ship. Their general smartness and intelligence has on more than one occasion put to shame young active service ratings. All are good 'mixers'. It has been a great surprise to all of us to observe how quickly they adapted themselves to what must be for them a very different life. I have been very favourably impressed by their high standard of conduct and general ability.'

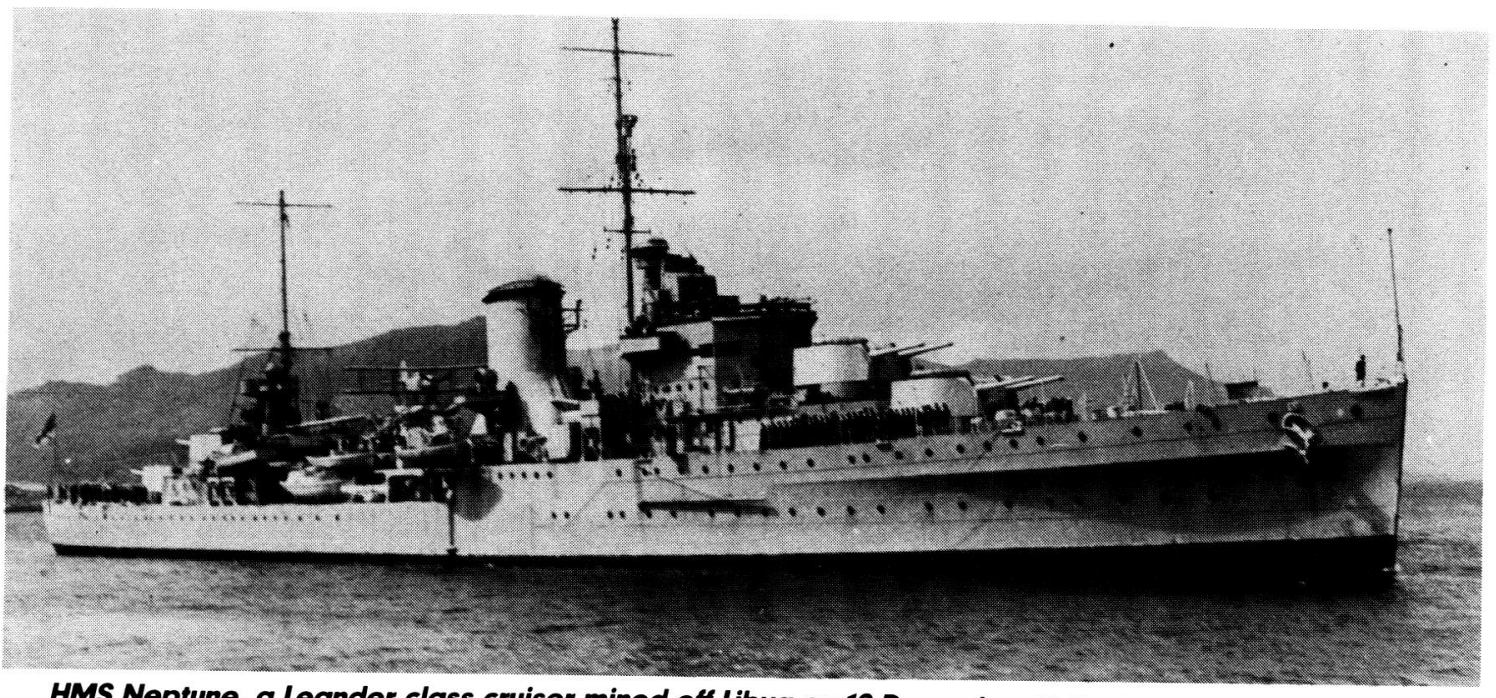

HMS Neptune, a Leander class cruiser mined off Libya on 19 December 1941. 18 South Africans were lost.

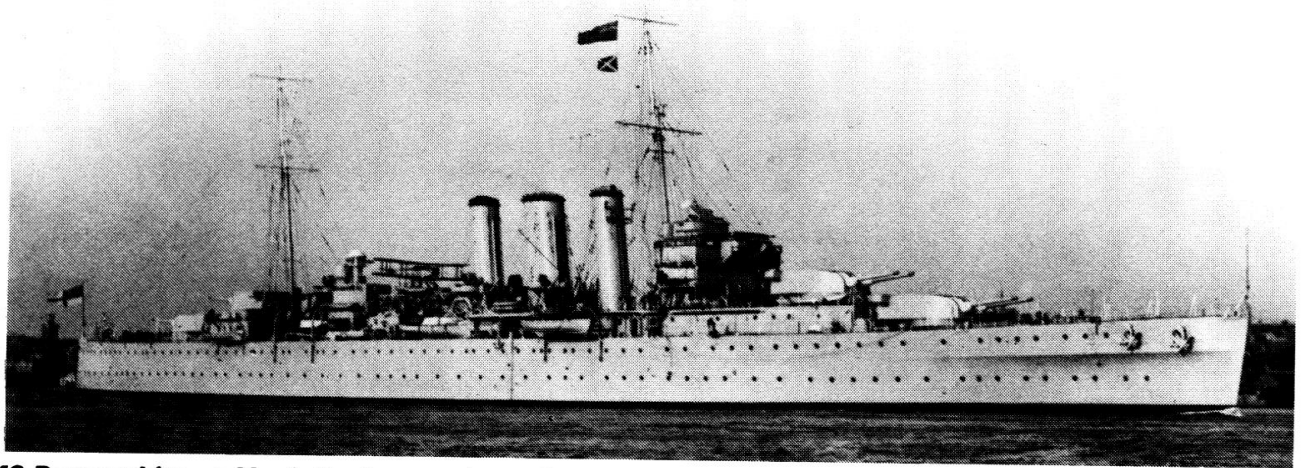

HMS Dorsetshire, a Norfolk class cruiser. On 27 May 1941 the Dorsetshire helped to sink the Bismarck. 
SECONDED SA NAVAL PERSONNEL 1940-1942

\begin{tabular}{|c|c|c|c|c|c|c|}
\hline $\begin{array}{l}\text { Ship or shore } \\
\text { Establishment }\end{array}$ & Type and class & \begin{tabular}{|c|} 
Officers \\
and mids \\
June 1940
\end{tabular} & $\begin{array}{c}\text { Ratings } \\
\text { June } 1940\end{array}$ & $\begin{array}{c}\text { Officers } \\
\text { and mids } \\
\text { Aug } 1941 \\
\end{array}$ & $\begin{array}{c}\text { Ratings } \\
\text { June } 1941\end{array}$ & $\begin{array}{l}\text { Officers } \\
\text { and mids } \\
\text { Aug } 1942\end{array}$ \\
\hline 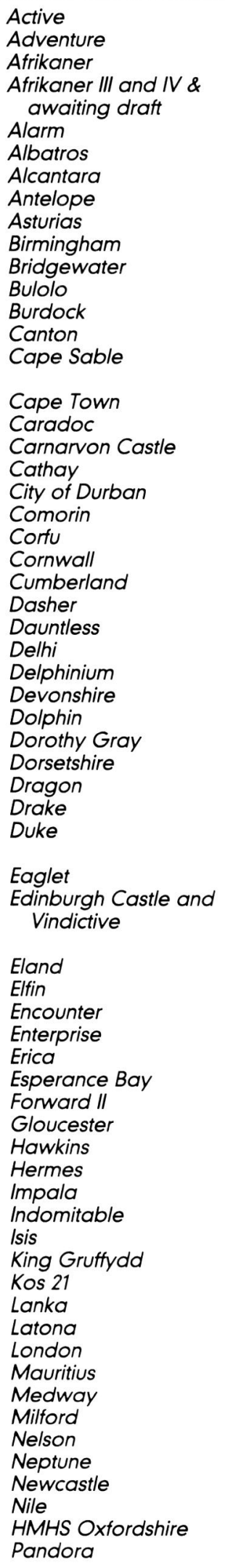 & 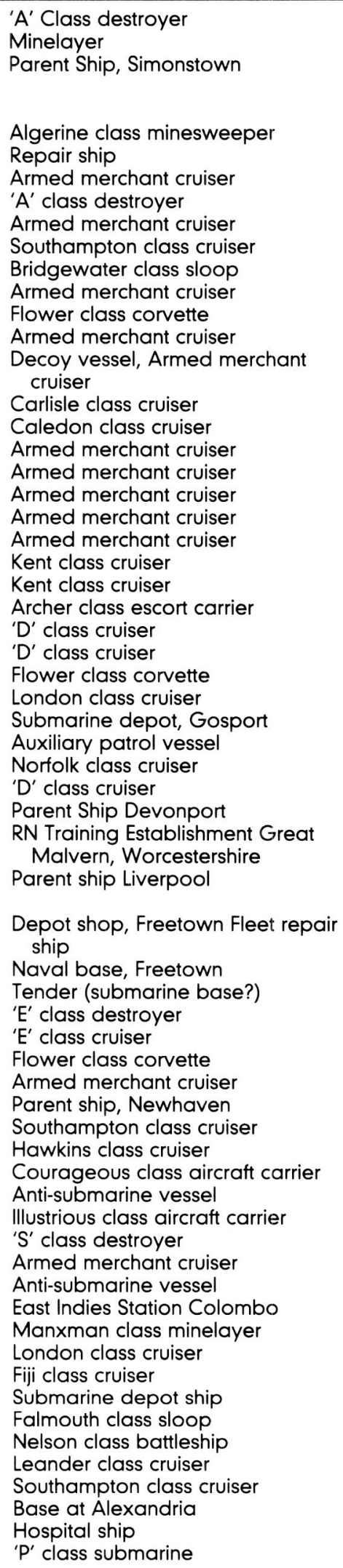 & & $\begin{array}{l}31 \\
18 \\
46 \\
24\end{array}$ & $\begin{array}{l}1 \\
1 \\
1 \\
3 \\
1 \\
1\end{array}$ & $\begin{array}{r}232 \\
93 \\
11 \\
5 \\
15 \\
13 \\
18 \\
21 \\
6 \\
6 \\
4 \\
1 \\
1 \\
44 \\
6 \\
6 \\
11 \\
6 \\
84 \\
87 \\
\\
25 \\
3 \\
22 \\
\\
66 \\
36\end{array}$ & $\begin{array}{l}1 \\
1 \\
1\end{array}$ \\
\hline
\end{tabular}


SECONDED SA NAVAL PERSONNEL 1940-1942

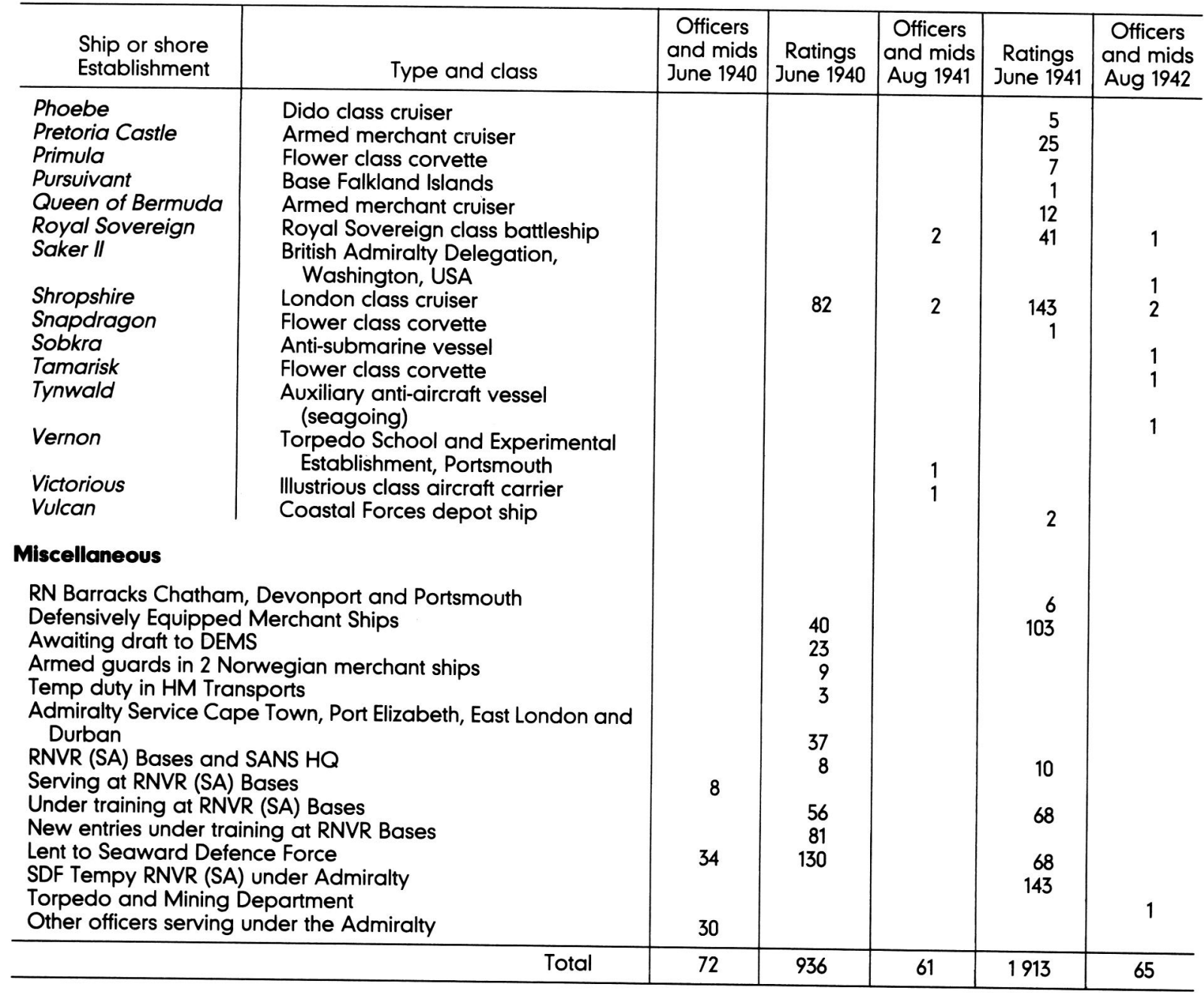

